Unity Journal

Vol. III, 292-304, 2022

Doi:https://doi.org/10.3126/unityj.v3i01.43333

Prithvi Narayan Shah Research Center

Directorate General of Military Training, Nepali Army

Kathmandu, Nepal

\title{
Use of Technology in Disaster Management
}

\section{Vijan Bhandari}

\begin{abstract}
Natural disasters are uncontrollable and cannot be avoided, although their effects can be mitigated in many ways, but human-caused catastrophes can be avoided and limited if people become more aware of their actions. Frequent occurrences of disasters have caused many casualties, destroyed physical properties, and created environmental damage which is raising concern in Nepal and the world as a whole. This study focuses at analyzing several technologies mainly on Robotics, Drone Technology, Mobile Phone and Social Medias, Internet of Technology and Artificial Intelligence that have been used and can be used for disaster management. These technologies are used in the three phases of disaster management, primarily the pre-disaster phase, disaster phase, and post-disaster phase, are explored to see how they can be used for predicting upcoming disasters, acting quickly and effectively during disasters, and analyzing the impact of disaster damage caused by disasters. This article would also be helpful to know about the development in technologies that have been achieved and further development that can be done to minimize the effect and casualties caused by disasters and also implement them in the necessary areas possible in our country as it is highly prone to the frequent occurrence of natural calamities.
\end{abstract}

Keywords: Disasters, Technology, Disaster Management, Disruptive Technologies

\section{Introduction}

\section{A. Disaster}

A disaster is a series of events, either natural or unnatural, that disrupt our daily lives and result in significant losses for individuals and communities as a whole (Panafrican Emergency Training Centre, 2002). According to various data and sources, the total number of disaster events documented in Nepal from 1971 to 2016 was 26,665, with 43,868 casualties and 2828 persons missing (Shrestha, 2019). Nepal is a very disasterprone country, with natural catastrophes striking on a regular basis. Floods, landslides, earthquakes, fires, thunder/hailstorms, and drought are all natural hazards that Nepal faces. In 2015, earthquakes displaced about 2.8 million people. In 2017, Over 190,000 homes were demolished or partially destroyed, displacing tens of thousands of people and causing many to become homeless due to flood (Department of Hydrology and Meteorology Flood Forecasting Division, 2018). Nepal saw three major flood in 2021 among which Melamchi Flood claimed the lives of five individuals and left 20 others missing, with the bulk of the flood-affected communities being physically devastated. In the same month, a flood destroyed three 
hydroelectric stations in the region, as well as an under-construction bridge in Mahakali. In September, a flood in the Terai area destroyed 382 buildings and wrecked numerous roads, while another flood in the Terai region killed nine people and damaged 42 homes (OCHA, 2021). In October, 103 casualties and 2600 people went missing due to flood with damage on 50,000 hectares of rice field and 2232 houses. Around Nepal, roads were blocked in 244 places, and reported damage was worth around 1 billion (Kantipur, 2021). Nepal has been rated one of the top 10 countries in the world for disaster-related fatalities, emphasizing the need of disaster management (CENTER FOR EXCELLENCE IN DISASTER MANAGEMENT \& HUMANITARIAN ASSISTANCE, 2020).

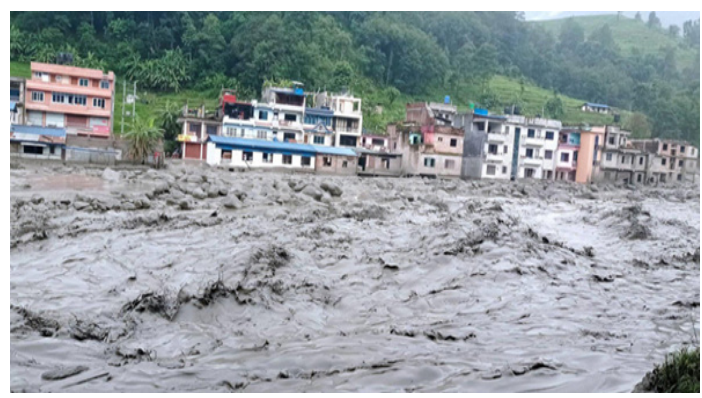

Figure 1: Melamchi Flood (Raja, 2021)

In Nepal, accidental fire is also a prevalent occurrence. Gas leaks, short circuits, abandoned cigarettes, and the burning of grass plantations are just a few of the reasons of fire accidents in Nepal. According to the Nepal Disaster Risk Reduction Portal, 12 fire accidents occurred in a single day on December 2, 2021, resulting in an estimated loss of 18 lakhs 77 thousand in property, 12 households directly impacted, and one house entirely burnt and four houses partially damaged. In the same week, another 37 fires were reported (Ministry of Home Affairs,
2021). In 2021, Nepal saw one of the biggest forest fires of the decade, with flames raging in 60 locations across 22 districts. Five people died, and the air quality in Kathmandu deteriorated to the worst level in the country, with the Air Quality Index hitting 400 on January 5 (Nepali Times, 2021).

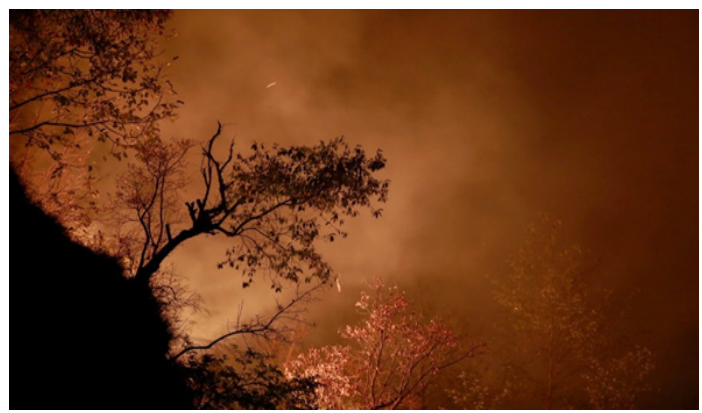

Figure 2: Forest Fire (Al Jazeera, 2021)

\section{B. Disaster Management}

Disaster management is the process of effectively planning for and responding to disasters and also analyzing the loss exposure during the event. It distributes resources to minimize harm and develops a systematic approach for disaster prevention, preparedness, response, and recovery. A natural disaster cannot be avoided, but its impact and destruction can be reduced with proper planning. Mitigation measures refers to the actions taken to lessen the severity of a disaster's impact. Mitigation and Prevention efforts aim to reduce the damages caused by disasters. (Tulane University School of Public Health and Tropical Management, 2021). Disaster preparedness saves lives, expedites recovery, and saves money. Pre-planning is required for well-coordinated disaster responses. This ensures that reaction activities are quick and efficient, with the least amount of repetition. Some disaster preparing phases include identifying organizational resources, assigning roles and duties, creating processes 
and policies, and planning actions to help with disaster readiness. Anticipating the requirements of disaster-affected populations makes response actions more successful. The capacity of volunteers, experts, and disaster management teams to respond to calamities improves the success of disaster response programs. The plan might include emergency shelter locations, evacuation routes, and emergency electricity and water supplies. This will also manage the distribution and storage of emergency supplies, as well as a chain of command, training programs, and communication mechanisms (The International Federation of Red Cross and Red Crescent Societies (IFRC), 2021) .

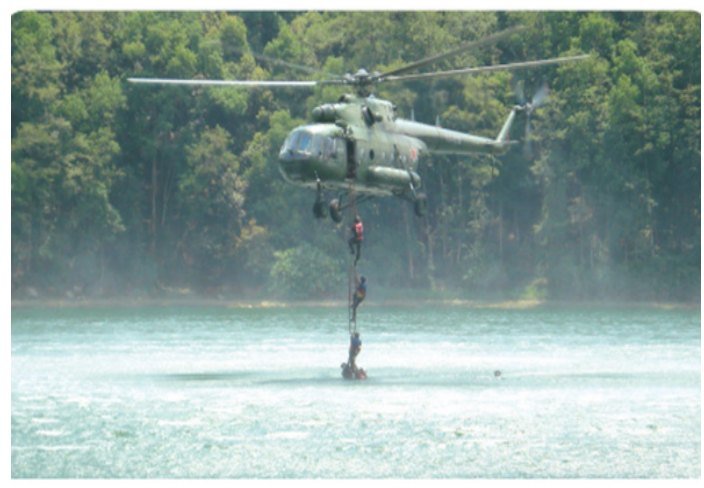

Figure 3: Nepal Army Search and Rescue Exercise (Nepal Army, 2021)

Disaster Management carries on to the stage of reaction and recovery after a disaster. During and immediately after a disaster, disaster management focuses on giving aid and activities that can save lives, preserve health, and safeguard buildings, animals, and common property. Disaster relief and rebuilding are the two main phases of disaster response and recovery. Evacuations, search and rescue activities, and emergency medical treatment are among the immediate demands of disaster-affected communities. The process includes providing a safe place to sleep, food, and emotional support from qualified workers, as well as providing meals and water, as well as distributing emergency goods and essentials, such as toiletries for hygiene and tarps, shovels, and trash bags for cleanup efforts, as well as providing emergency health services, such as first aid for injuries and prescription medication replacements. Meanwhile, throughout the reconstruction phase, management or the government assists the community in rebuilding following a disaster by providing different forms of aid (Tulane University School of Public Health and Tropical Management, 2021).

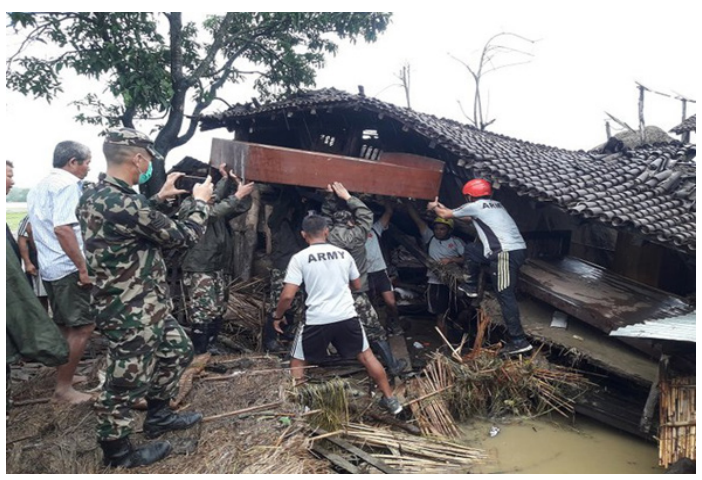

Figure 4: Disaster Response by Nepal Army (New Spotlight Nepal, 2021)

\section{Technology}

Technology is the practical application of information to make a task easier and faster, and it plays an important part in crisis prevention, planning, and management. Remote sensing, satellite communication, GPS, and GIS technologies, as well as the Internet of Things, have all helped to the design and execution of risk reduction programs, as well as enhanced the management of largescale disasters (Habib \& Baudoin, 2010). Communication, data analysis, and security are all required for disaster preparedness and prevention. Human safety and security, as well as job efficiency, productivity, and flexibility, 
may be improved by robotics systems built to function in adverse environments. Robotic mechanics and mobility, sensors and sensor fusion, autonomous or semi-autonomous navigation, and machine intelligence are all obstacles in addressing and satisfying the demands of such operations (Milosh, 2020).

\section{Critical Discussion}

Emerging technology has the potential to transform disaster management if correctly integrated with present infrastructure. Artificial intelligence (AI), the Internet of Things(IoT), Big Data, drones, and blockchain will all help to improve disaster response and assistance. Disruptive technologies can help with the faster transmission of essential information, a better understanding of catastrophe causes, improved early warning systems, creative damage assessment, and the addition to the knowledge base of social behavior and economic ramifications following a disaster. While the use of drones and the Internet of Things is increasing, older technologies like satellite imagery and seismometers are still the most important tools for detecting, monitoring, and accessing catastrophes (Minges, 2019).

The overview of technologies for disaster management is discussed in this document. Some of these technologies include:

\section{A. Robots}

A robot is a machine that is programmed to do one or more activities frequently and accurately and can be used in areas affected by disasters that are too dangerous for humans. Reconnaissance and mapping, structural assessment, high-rise building fire response, chemical, biological, radiological, and nuclear events, search and rescue operations, risk assessment, and logistics support are all areas where robotics can help (Eastern Kentucky University, 2021). During 2001 terrorist attack in New York City, search-and-rescue robots were initially deployed to survey the ruins of the World Trade Center. As of 2018, robots are deployed for more than 50 disaster events (Minges, 2019). Japan has been a forerunner in the employment of robots in catastrophes. Tohoku University's HumanRobot Informatics Laboratory is working on numerous sorts of disaster-response robots (Human-Robot informatics Laboratory, TOHOKU University, 2021). Some of them include:

i. SAR (Search and Rescue) dogs are capable of locating people in disaster zones in as little as 72 hours. Still, SAR dogs are not employed in genuine rescue missions in Japan. Onefactor is the scarcity of footage and data demonstrating the effectiveness of SAR dog investigations. However, the activities of SAR dogs are recorded and actions are visualized using cameras, GPS, and inertial measurement units (IMU).

ii. RoboCup Rescue is a tournament in which teleoperated or autonomous robots are used to search for simulated victims in a fallen building. The competition needs a rescue robot system with entire integrity, including high mobility over debris and stairs, reliable communication, an easily navigable interface, a strong mapping system, and highly competent operation.

iii. The snake-like Active Scope Camera is wrapped in minuscule vibrating filaments that allow it to crawl over obstacles, follow walls, and pivot in confined areas. Its design allows it to dig through the wreckage for survivors in a train crash, and it can also identify noises, such as 
individuals trapped in collapsed houses.

iv. After a calamity, Kenaf can investigate a damaged structure, subterranean facility, or unstable terrain. Kenaf is a robot that enters a $60 \mathrm{~cm}$ diameter hole and uses wireless connectivity to gather pictures, noises, and $3 D$ objects.

v. Quince is a mobile robot featuring four pairs of tracked wheels, some of which may move up and down to help it navigate obstacles. It's equipped with cameras, infrared, and carbon dioxide sensors to identify the existence of people buried beneath the wreckage.

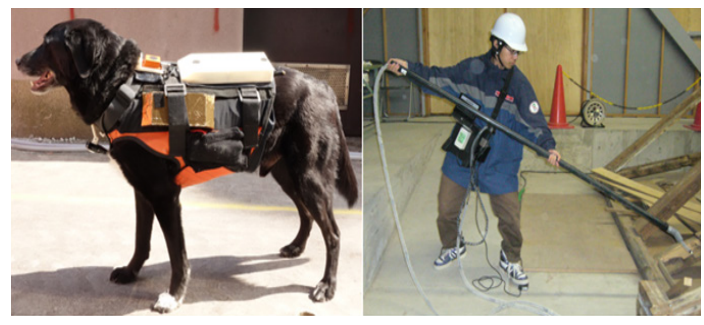

Figure 5: SAR Dogs and Active Scope Camera developed by Human-Robot informatics Laboratory, TOHOKU University (HumanRobot informatics Laboratory, TOHOKU University, 2021)

MIT's Biomimetic Robotics Lab has developed a robot called Cheetah III for earthquake rescue operations and the dangerous radiation-affected regions. It can jump 60 centimeters in height moving at 6.4 meters per second and can avoid obstacle on its way. The cheetah has undergone several modifications intended at improving load capacity, range of motion, and even grasping agility (Brown, 2018). Similarly, RoboBees, small Harvard-developed bots utilize electrostatic stickiness after an earthquake, to analyze walls and ceilings, assessing damage on structure (President and Fellows of Harvard College, 2021). To tackle fires,
Mitsubishi Heavy Industries (MHi) uses fully autonomous robots. The MHi Water Cannon Bot extinguishes fires in exceedingly dangerous environments. The Cannon Bot and its companion Hose Extension Bot can spray foam or water at a rate of 4,000 liters per minute at a pressure of 1 megapascal $(\mathrm{MPa})$, and they're even part of a wider AI-driven system for reconnaissance and surveillance on larger cargo vehicles. As the flames get more aggressive, high-volume production of these bots can decrease casulties. Systems like MHi's Cannon Bot, when paired with predictive AI forest fire mapping and autonomous carrying vehicles, will not only save many lives but will also avoid population displacement and catastrophic devastation to our natural ecology before a disaster happens (Mitsubishi Heavy Industries Limited, 2019). In 2017, Japan created the "Little Sunfish," a little robot with five propellers, video cameras, and a variety of sensors that allowed it to function underwater while being exposed to high levels of radiation and was effective in discovering the reactor's lost fuel inside the core (Minges, 2019).

\section{B. Drones}

Drones are flying robots and part of unmanned aircraft system (UAS) that use inbuilt sensors and GPS to fly independently. They can be operated remotely or by employing flight plans that are controlled by software. Drones can be used for several civilian and military missions, including search and rescue, surveillance, traffic monitoring, weather monitoring, firefighting, giving relief supplies, videography, agricultural, and a variety of other tasks. In the case of wildfires and conflict zones, autonomous drone technology is radically changing the way we discover individuals in need and automate assistance delivery. Drones are used 
by firefighters to inspect an affected region in order to estimate the level of damage and the rate at which a fire is developing. Drones can also find persons who are isolated faster than ground-based rescue teams (Lutkevich \& Earls, 2021). With Nepal facing much of the wildfire problem recently, drones can come in handy to the firefighters due to these reason. Studies are going on in accessing drones in preventing an animal attack. As of an online report by Beverley Head in ComputerWeekly.com, the studies is going on to detect crocodiles lurking in the water so that crocodile attack could be minimized and prevented using drones and machine learning.

The major areas where drones can be used in disaster management are:
The use of drones for damage assessment was implemented when Cyclone Pam struck the nation of Vanuatu in 2015. The cyclone destroyed 1000s of buildings and 75 thousand people were homeless. With cloud disturbing the satellite images, drones were used to evaluate the damage that occurred by the cyclone. The image from drones helped to determine the infrastructures that were completely damaged, partially damaged, and undamaged. The problem of connectivity was the big issue but drones managed to provide the mapping of damaged areas. This also helped the government to plan and allocate a budget for the relief package and rebuilding after the cyclone and supply required materials, medicines, and food (Minges, 2019).

\section{i. Mapping/Damage Assessment}

In the context of disaster management, drones are highly valuable for monitoring, mapping, and damage assessment. It has been used widely in floods, landslides, forest fires, tsunamis, cyclones, earthquakes as well nuclear accidents. Drones take better photos in less time than satellite pictures and GPS surveys, making them more efficient than first responder data. The construction of a web-based drone aerial photo-sharing system improves information sharing efficiency during the early stages of disasters which is very useful for assessing erosion and floods because they supply detailed and continuous $2 \mathrm{D}$ and $3 \mathrm{D}$ data while requiring very little on-site time. Furthermore, it can create a 3D model of the disaster site with the help of different software (Daud, et al., 2021).

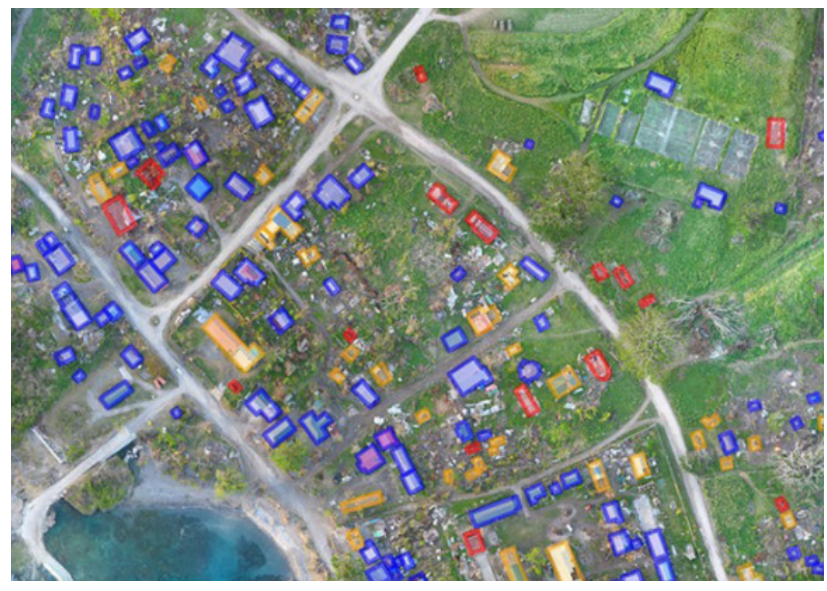

Figure 6: Mapping Damage after Cyclone (Irwin, 2015)

In the figure, the structures marked red are heavily damaged, yellow-marked is partially damaged and blue marked are undamaged.

\section{ii. Search and Rescue}

Drones have been employed at high altitudes and in extreme places to reduce 
response and evacuation times while ensuring responder safety, as well as to locate buried people. Drones were used to confirm a fatality in a slot canyon, removing the need for rescuers to risk a night rappel. It also made it easier to search in locations that groundskeepers couldn't get to (Tilburg, 2017). Search and Rescue of lost climbers in the Karakoram Mountains of northeastern Pakistan became quicker because of drones (N.McRae, J.Gay, M.Nielsen, \& P.Hunt, 2019). The search in larger areas in short times can be possible with assistance from drones which improves search and rescue missions. The use of drone data to identify cardiac motion induced by the victims' recurrent chest movement has been proposed as a way of detecting victims. The technology accurately identifies indications of life in a range of stances, indicating that it has the potential to be used in future Search and Rescue missions (Al-Naji, Asanka, Mohammed, \& Chahl, 2019). The method has also been proved to be effective in locating victims at sea. Drone technology combined with GNSS (Global Navigation Satellite System), real-time computer vision, and deep learning algorithms might allow drones to provide accurate support to first responders in a timely manner. A novel technique for searching for missing individuals across a large territory that employs a swarm of drones rather than a single drone has been found to be effective in reducing costs and time while enhancing or preserving the quality of Search and Rescue operations. The use of a team of drones has the potential to save the greatest number of people in the shortest amount of time. As the number of drones climbs, the layered search and rescue (LSAR) algorithm increases the proportion of rescuers (Alotaibi, Alqefari, \& Koubaa, 2019).

People can become trapped in the rubble as a result of natural disasters such as earthquakes or explosions. During floods, people may become stranded in areas with no safe route out, such as roofs or top-floor rooms. Similarly, in search and rescue operations, terrain, such as mountain ranges or large swathes of the natural environment, can be difficult to navigate. Drones used in search and rescue efforts are frequently outfitted with thermal imaging cameras, which can aid in the search for missing people in difficultto-reach places. This not only enhances their accuracy in aiding in the search for survivors but also reduces the cost and risk of bringing in rescue helicopters in the first place (Oliver, 2020).

\section{iii. Supplying medicals and essential items}

Often in the post-disaster phase, the communication lines, transportations, as well as supply lines, are heavily disturbed. That is where drones can play an important role in supplying essential items including medicines. Even in a normal scenario, delivery by air is faster than delivery from land transport. In Rwanda and Tanzania, drones have directly provided access to 11 million people with instant medical supplies as well as life-saving materials like blood, plasma within an hour (Diamandis, 2019). During Covid-19 Pandemic, drones became handy in supplying masks, PPA kits as well as vaccines in different places faster. 


\section{iv. Disaster recovery}

Drones could help disaster recovery go more quickly and safely. Without having to go to such locations, measurements of damaged and vulnerable structures may be taken, and photos of the damage can be sent to the proper authorities. Drones can help with the safety evaluation of infrastructure in the wake of earthquakes, floods, and fires, allowing repairs to be completed more quickly than if they were done by hand. Drones are increasingly being used in the construction industry to inspect and monitor constructions and sites for safety and development (Oliver, 2020).

\section{Mobile Phones and Social Medias}

In the past few decades, there has been massive development in mobile phones and telecommunication. With the development of mobile phones, their functionality and uses have also improved a lot. Today majority of mobile phones have a function of the camera, internet, and location service with them. These functions play a rapid role in disaster management. Using mobile phones, victims can contact their friends, families, relief workers, or concerned authorities in time of disaster. When calls are overloaded, SMS or text messages can be sent. Usually, a TollFree number and text message service are provided by the government for free where we can report about disasters or accidents like fire. In Nepal dial 100 for contacting police, 102 for the ambulance, and 101 for the fire brigade. Even the concerned authorities, the government can use the help of SMS to send the important information about safety and relief during a disaster or to warn the people about upcoming disasters like floods or landslides based on the information available.
The Government of Nepal Ministry of Home Affairs sends SMS warnings about possible floods or landslides when the water level in the major rivers exceeds the safety level during rainy seasons. Caller back tune can also be used to inform the people about the possible disasters or impact or disaster and share the information about the disasters and pandemics. Nepal Telecom with the Ministry of Health has played a great role during Covid-19 in giving the awareness and safety measures of the Corona Virus pandemic as an automatic caller back tune.

Social Media is another tool that can greatly improve the disaster management role. The information on social media amplifies and in many cases it spreads among the people faster than the daily newspaper, TV News, or radio. Hence, sharing awareness and information about the disaster and household accidents like short circuits, gas leakage fires, information regarding pandemics using social media can be very fruitful. There is a video about what to do when a gas cylinder catches fire by the Nepal Army that appeared on Facebook which shows that instead of pouring water in the LPG during a fire, it is better to cover it up with a blanket which would prevent fire from catching oxygen and it would extinguish itself. Water on the other hand could provide oxygen that could amplify the fire. It also showed many other safety protocols and steps to be followed on what must be done during a fire. These kinds of informative videos can help to greatly minimize the risk of fire and sometimes it can be controlled before it can cause heavy damage. 


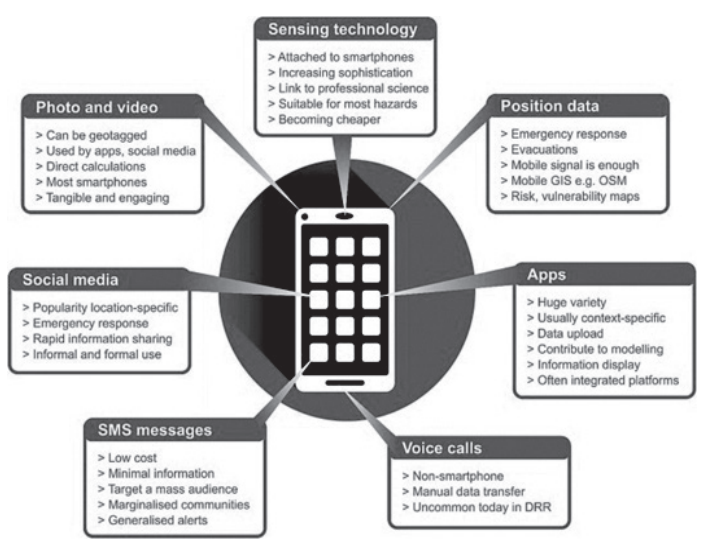

Figure 7: Features in Mobile Phone that can help in disaster (Paul, Bee, \& Budimir, 2021)

Facebook has a feature of crisis response that helps to know if the people living in the disaster zone are safe or are in need of some help. This feature was widely used in Nepal during the 2015 earthquake. This feature helps to provide immediate support in the required area and access the information of the victims. The news about the disaster will quickly spread around the maximum users which would help in crowdsourcing, fund collection, and providing relief materials quickly.

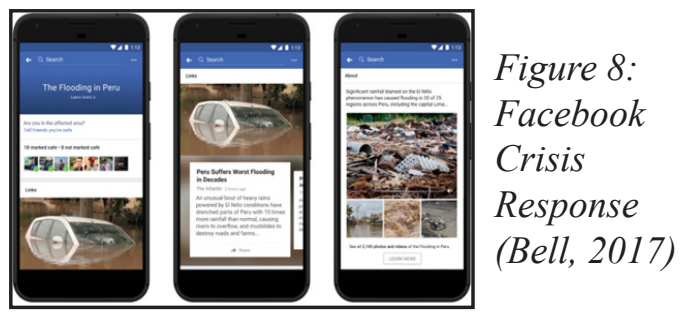

The flood in Chennai in 2015 saw the massive use of social media in disaster response when there was an overload of the telephone. The rainfall that occurred was one of the worst in 100 years which caused the flood. Various organizations have utilized Twitter and Facebook for a variety of purposes. The Twitter live, a real-time public platform was utilized by NGOs, the general public, government agencies, and the media to distribute and share information. As a result, the platform witnessed unprecedented collaboration in the aftermath of the accident. Twitter India has recommended three hashtags to use during the flood, depending on the content of the tweet: Using the hashtags \#ChennaiRainsHelp, \#ChennaiRescue, and \#ChennaiVolunteer, citizen groups may assist authorities on the ground. Among the goods supplied were helpline phone numbers, altered rail schedules, weather forecasts, humanitarian operations, and safety tips. This helped in amplifying important messages, organizing relief activities, supporting government agencies, alerting the public, and giving flood victims' real-time information. The government, police, and public utilized a Google spreadsheet to crowdsource information regarding shelter, weather, and other valuable tips (Minges, 2019).

\section{Internet of Things}

Internet of Things refers to sensors, cloud computing, wireless network, and big data analysis emerging into the real-time, integrated and powerful system. Different sensors placed on different places like waters, soil, hills, forest can send a signal about a potential disaster which would alert the community and nation to apply a safety measures quickly before any harm could be done by disasters which can prevent a lot of casualties and economic loss. IoT is also used as a smoke sensor, fire alarm, ultrasonic sensor on vehicles to avoid any kind of accidents happening. Temperature, moisture, and carbon dioxide levels may all be measured by tree sensors to see if a fire has started. Sensors on the ground like seismic sensors can detect earth movements that might indicate an earthquake. Machine learning 
is being used by scientists at the Los Alamos National Laboratory in the United States of America to experiment with prediction approaches, whereas Japan based Kyoshin Network has already studied and developed these sensors and implemented on different zones for earthquake detection. Sensors can be used to monitor river levels for impending floods (Minges, 2019).

The application of IoT was seen in Columbia in 2017. Following

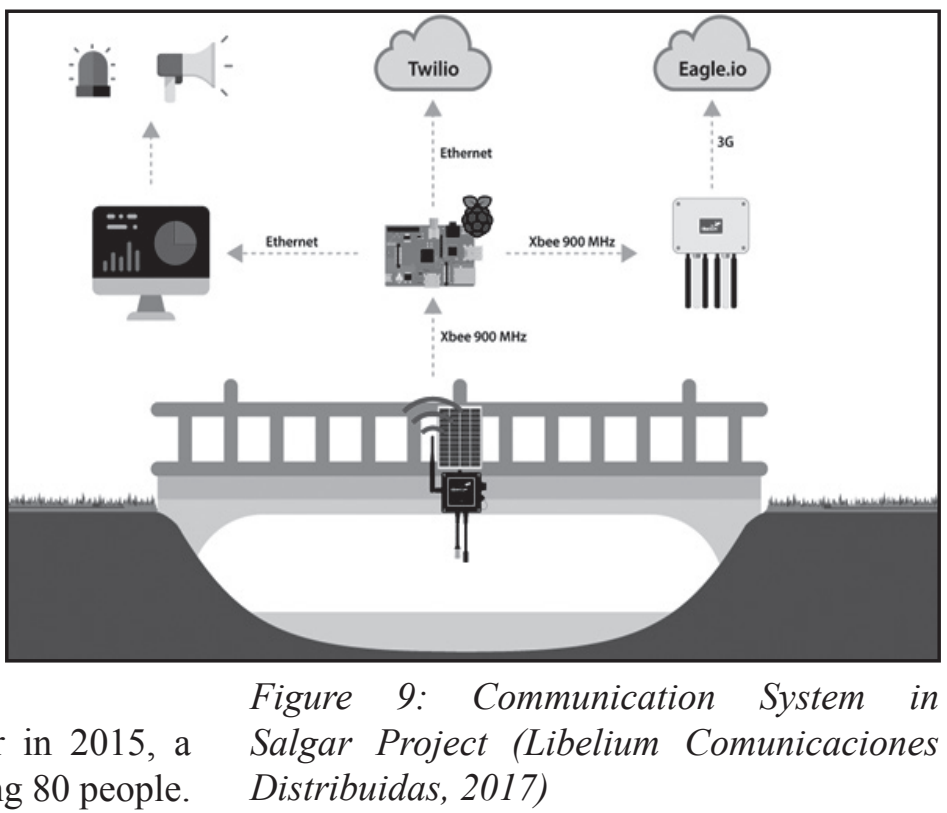
a flood on the Liboriana River in 2015, a horrific landslide occurred, killing 80 people. To avoid future damage, the government has opted to employ IoT technology. To monitor water levels and air temperature using ultrasound, five solar-powered sensors were set along the Liboriana and two additional rivers. In the municipality and flood threat zones, sirens have been erected. Due to the mountainous terrain and spotty $3 \mathrm{G}$ coverage, communication among the sensors was difficult. As a result, a $900 \mathrm{MHz}$ mesh network was established, allowing the sensors to broadcast data to the village control center, where local officials could observe and analyze the situation and determine if the early warning system is to be activated. Data is also kept in the cloud at the distant sensor location, where it may be accessed by others. Upon any signal of hazards, it automatically sends SMS to communities living nearby. The government has spent around 130 thousand USD to develop and implement this system which became very much helpful in predicting upcoming floods and landslides (Libelium Comunicaciones Distribuidas, 2017).

\section{E. Artificial Intelligence}

Development in Artificial Intelligence can be a booster in disaster management role. Using large sets of algorithm and data, AI helps in prediction of disaster as well as improve recovery and response time. AI analysis was utilized to detect damage to dwellings in the 2011 Tohoku earthquake. The effort was done to figure out where residences that were wiped away by the tsunami were located. With a 94 percent accuracy rate, the AI was able to locate the afflicted homes. AI was also used to identify landslides after the 2018 Hokkaido earthquake in Japan. Comparing with visual interpretation, AI with $93 \%$ accuracy could detect damaged places in 5 minutes. Skilled engineers took roughly 5 days to determine damaged places with deceptive sites (Development Asia, 2021). Universities and researchers are currently focusing to develop AI in prediction of an earthquake as there are large number of seismic data available. Computer software are used instead of seismometers to precisely 
locate epicenters which examine waveforms in conjunction with previous events which are analyzed using cross-correlation and multievent location software (Minges, 2019).

In several natural catastrophes throughout the world, Artificial Management for Disaster Response has been shown to be beneficial. Technology enables individuals to respond to such situations swiftly and effectively, saving countless lives in the process. These intelligence systems have shown to be highly effective in anticipating earthquakes and rapidly informing prospective victims of approaching calamities. As a part of Artificial Intelligence Disaster Response (AIDR), Qatar-based computing research institute has developed an online tool that focuses on the effective utilization of volunteers and agencies for disaster management by identifying tweets related to calamities using machine learning. Another company named 1CONCERN creates a single and complete image for use by emergency operations centers during emergencies and provides resources for rescue operations. It trains its volunteers using modules that simulate real-life crises. The module also identifies disaster-prone areas that could be most affected during a natural disaster. It has mapped over 163,696 square miles and has reached over 39 million individuals. In addition, it has modeled 14,967 fault lines and assessed approximately 11 million buildings. This enables the program to be prepared and aware in the event of a natural disaster. AIDR was implemented in Nepal during a massive earthquake in 2015. It filtered and classified all the tagged tweets that were posted during the crisis into urgent need, infrastructure damage, and need of resource deployment. This helped to effectively mobilize all the volunteers deployed by Digital Humanitarian
Network's member organizations known as Standard Task Force (STF). In this way, the use of AI makes disaster management quick, safe, and effectively organized (Eastern Kentucky University, 2021).

\section{Conclusion}

The development of technologies is only going to further assist in effective disaster management. There is so much research going on around the world in the various technologies to detect and predict upcoming disasters, ways and steps for acting and responding quickly during a disaster, and further analysis and discussion on the rebuilding process aftermath of disasters. The paper has discussed and reviewed different technologies that have been developed as well as technologies that are in the research and development phase. Some of these technologies have been used and implemented in Nepal as well during an earthquake in 2015, floods, and landslides. The article only consists of the positive impact of technologies in disaster management and there are many drawbacks of technology as well. Further, there are many more literature available which would further give more insights about the topics. Due to the time constraints and technical difficulties, the project to develop and implement early warning system for creep landslides could not be completed hence this article focuses more on the case studies of different calamities that has occurred in the past and application of various technologies for its effective management.

\section{References}

Al Jazeera. (2021, April). Nepal Battles Worst Forest Fires in Years as Air Quality Drops. Al Jazeera News. Retrieved from Al Jazeera Website: https://www.aljazeera.com/ news/2021/4/9/nepal-battles-worst-forest- 
fires-in-years-as-air-quality-drops

Al-Naji, y. A., A. G., Mohammed, S. L., \& Chahl, J. (2019). Life Signs Detector Using a Drone in Disaster Zones. Remote Sens.

Alotaibi, E. T., Alqefari, S. S., \& Koubaa, A. (2019). LSAR: Multi-UAV Collaboration for. IEEE Access.

Bell, K. (2017, September). Facebook wants you to check its new 'Crisis Response' feature when disaster hits. Retrieved from Mashable Incorporation: https://mashable.com/article/ facebook-crisis-response

Brown, E. (2018, March 26). MIT News on Campus and Around the World. Retrieved from Massachusetts Institute of Technology Campus Newsletter Website: https://news. mit.edu/2018/cheetah-robot-preps-role-firstresponder-sangbae-kim-0326

Center for Excellence in Disaster Management \& Humanitarian Assistance (2020). Disaster Overview. Nepal Disaster Management Reference Handbook.

Daud, S. M., Heo, C. C., Yusof, M. Y., Khoo, L. S., Singh, M. K., Mahmood, M. S., \& Nawawi, H. (2021). Applications of drone in disaster management: A scoping review. Science \& Justice, 38.

Department of Hydrology and Meteorology Flood Forecasting Division. (2018). Standard operating procedure (SOP) for flood early warning system in Nepal. Kathmandu: Government of Nepal Ministry of Energy, Water Resources and Irrigation.

Development Asia. (2021, March). How AI Can Boost Disaster Response and Recovery. Retrieved from Asian Development Bank Insight : https://development.asia/insight/ how-ai-can-boost-disaster-response-andrecovery

Diamandis, P. H. (2019, April 12). AI and Robotics Are Transforming Disaster Relief. Retrieved from Singularity Hub: https://singularityhub. com/2019/04/12/ai-and-robotics-aretransforming-disaster-relief/
Eastern Kentucky University. (2021, December 6). Robots and Drones Saving Lives in Disaster Areas. Retrieved from EKU Online: https:// safetymanagement.eku.edu/blog/robots-anddrones-saving-lives-in-disaster-areas/

Eastern Kentucky University. (2021). The Benefits \& Challenges of Using Artificial Intelligence for Emergency Management. Retrieved from EKU Online: https://safetymanagement. eku.edu/blog/the-benefits-challenges-ofusing-artificial-intelligence-for-emergencymanagement/

Habib, M. K., \& Baudoin, Y. (2010). RobotAssisted Risky Intervention, Search, Rescue and Environmental Surveillance. International Journal of Advanced Robotic Systems, 2.

Human-Robot informatics Laboratory, TOHOKU University. (2021, December 8). Rescue System. Retrieved from Human-Robot informatics Laboratory Website: https://www. rm.is.tohoku.ac.jp/rescue+systems/

Irwin, M. (2015). Mapping Cyclone Pam's destruction with drones. Vanuatu.

Kantipur. (2021, October 24). बेमौसमी वर्षाले सडकमा $q$ अर्ब $y$ करोडको क्षति. Retrieved from kantipur: https://ekantipur.com/news/2021/10 /24/163506029734683079.html

Libelium Comunicaciones Distribuidas. (2017, December). Early warning system to prevent floods and allow disaster management in Colombian rivers. Retrieved from Libelium Comunicaciones Distribuidas Website: https:// www.libelium.com/libeliumworld/successstories/early-warning-system-to-preventfloods-and-allow-disaster-management-incolombian-rivers/

Lutkevich, B., \& Earls, A. R. (2021, December). IoT Agenda . Retrieved from Tech Target: https://internetofthingsagenda.techtarget.com/ definition/drone

Milosh, A. (2020, July 27). Roles of Information Technology in Emergency Preparedness and Prevention. Retrieved from Atera Website: 
https://www.atera.com/blog/10-roles-ofinformation-technology-in-emergencypreparedness-and-prevention/

Minges, M. (2019). Disruptive technologies and their use in disaster risk reduction and management 2019. Balaclava, Mauritius: International Telecommunication Union.

Ministry of Home Affairs. (2021, December 3). Nepal Disaster Risk Reduction Portal. Retrieved from Nepal Disaster Risk Reduction Portal Website: http://drrportal.gov.np

Mitsubishi Heavy Industries Ltd.. (2019, March). MHI Develops Autonomous "Water Cannon Robot" and "Hose Extension Robot" for Use in Firefighting. https://www.mhi.com/ news/190325.html

N.McRae, J., J.Gay, C., M.Nielsen, B., \& P.Hunt, A. (2019). Using an Unmanned Aircraft System (Drone) to Conduct a Complex High Altitude Search and Rescue Operation: A Case Study. Wilderness \& Environmental Medicine.

Nepal Army. (2021). Nepalese Army and Disaster Management. Kathmandu: Nepal Army Military Journal.

Nepali Times. (2021, January). Kathmandu Pollution Hits Record High. Nepali Times. Retrieved from Himalmedia Pvt Ltd Website: https://www.nepalitimes.com/latest/ kathmandu-air-pollution-hits-record-high/

New Spotlight Nepal. (2021, July). Nepal Army Launches Rescue And Relief Operation To Save People From Landslide And flood. New Spotlight Nepal. https://www.spotlightnepal. com/2021/07/09/nepal-army-launchesrescue-and-relief-operation-save-peoplelandslide-and-flood/

OCHA. (2021, September 7). Asia and the Pacific: Weekly Regional Humanitarian Snapshot (31 August - 6 September 2021). UN Office for the Coordination of Humanitarian Affairs. Retrieved from Asia and the Pacific: Weekly Regional Humanitarian Snapshot (31 August - 6 September 2021): https://reliefweb. $\mathrm{int} / \mathrm{report} / \mathrm{nepal} / \mathrm{asia-and-pacific-weekly-}$ regional-humanitarian-snapshot-31-august-6september-2021

Oliver, F. (2020, October 20). Six ways drones are helping in emergency response. https:// www.soarizon.io/news/six-ways-drones-arehelping-in-emergency-response

Panafrican Emergency Training Centre. (2002). Disasters and Emergencies. Addis Ababa: World Health Organization.

Paul, J. D., Bee, E., \& Budimir, M. (2021). Mobile Phone technologies for disaster risk reduction. Climate Risk Management.

President and Fellows of Harvard College. (2021). RoboBees: Autonomous Flying Microrobots. Retrieved from Hansjörg Wyss Institute for Biologically Inspired Engineering at Harvard University Website: https://wyss.harvard.edu/ technology/robobees-autonomous-flyingmicrorobots/

Raja, M. (2021, August 1). Saturday Night Floods in Melamchi caused significant infrastructure damage. The Kathmandu Post . Retrieved from The Kathmandu Post Website: https://kathmandupost.com/provinceno-3/2021/08/01/saturday-night-floods-inmelamchi-caused-significant-infrastructuredamage

Shrestha, B. R. (2019). An Assessment of Disaster Loss and Damage in Nepal. Kathmandu: The Geographic Base Vo. 6.

The International Federation of Red Cross and Red Crescent Societies (IFRC). (2021). Disaster Preparedness. Retrieved from IFRC Website: https://www.ifrc.org/disaster-preparedness

Tilburg, C. V. (2017). First Report of Using Portable Unmanned Aircraft. Wilderness and Environmental Medicine, 1.

Tulane University School of Public Health and Tropical Management. (2021, September 3). What Is Disaster Management? Understanding Emergencies From Prevention to Mitigation. Retrieved from Tulane University School of Public Health and Tropical Management Website: https://publichealth.tulane.edu/blog/ what-is-disaster-management/ 